\title{
Las cooperativas prestadoras de servicios públicos en Argentina. Noción. Tensión de los principios cooperativos. Desarrollo. Contribución social. Principales desafíos que enfrentan
}

\author{
Patricia A. Fernández Andreani ${ }^{1}$ \\ patriciafandreani@yahoo.com.ar
}

\begin{abstract}
Sumario: 1. ¿Qué son las cooperativas prestadoras de servicios públicos?-2. Los principios cooperativos: su adaptación a las cooperativas prestadoras de servicios públicos y las tensiones que genera. a) Principio de libre ingreso y adhesión voluntaria. b) Principio de control democrático. c) Principio de participación económica. d) Principio de autonomía e independencia. e) Principio de educación, capacitación e información. f) Principio de cooperación entre cooperativas. g) Principio de la preocupación por la comunidad.-3. Desarrollo del cooperativismo de servicio público en Argentina.-4. Contribución social del cooperativismo de servicio público.-5. Principales desafíos que enfrenta este modelo de gestión en la posmodernidad. 5.1. La necesidad de que se reconozca en los contratos de concesión y normas regulatorias la naturaleza de la entidad con medidas eficaces que garanticen la ecuación económica financiera del servicio. 5.2. Adaptarse y adelantarse a los cambios tecnológicos. 5.3. Generar políticas de integración asociativa y ampliar los horizontes de participación de los asociados. 5.4. Sensibilizar sobre la necesidad de contar con nuevas herramientas para el financiamiento y la capitalización de estas entidades.-6. Conclusiones.-Bibliografía.
\end{abstract}

Resumen: El modelo cooperativo de servicio público ha conseguido un gran desarrollo en Argentina en el siglo Xx. Lo distintivo de estas organizaciones es que los usuarios se organizan a través de una empresa democrática para prestarse un servicio de alcance general y de interés colectivo. La contribución social de estas organizaciones excede la mera satisfacción del interés del asociado y se expande permitiendo una mejor calidad de vida del conjunto de los

Abogada, Doctora en Derecho por la Universidad de Valencia, España, Tesis doctoral dirigida por la Profesora Isabel Gemma Fajardo, Diplomada en Altos Estudios Europeos, Máster en derecho de la Empresa de la Universidad Austral, Profesora de Doctorado y Pos Doctorado de la UMSA y docente de la UBA. Autora de numerosas publicaciones y libros especializados en Derecho Comercial y Cooperativo. 
ciudadanos. En tiempos de crisis estas organizaciones han actuado como verdaderos colchones sociales.

El mantenimiento y la supervivencia de estas entidades dependerá de las adaptaciones que exigen los tiempos actuales. El presente trabajo procura identificar los nuevos desafíos y proporcionar algunas soluciones normativas, regulatorias y de buen gobierno.

Palabras clave: Empresas comunitarias, servicios públicos, empresas de la economía social.

Abstract: The cooperative model of public service has achieved great development in Argentina in the 20th century. What is distinctive about these organizations is that users organize themselves through a democratic company to provide a service of general scope and of collective interest. The social contribution of these organizations exceeds the mere satisfaction of the interest of the associate and expands allowing a better quality of life for all citizens. In times of crisis these organizations have acted as true social buffers.

The maintenance and survival of these entities will depend on the adaptations required by current times. This summary tries to identify the new challenges and provide some normative, regulatory and good governance solutions.

Keywords: community company, public services, social economy company. 


\section{1. ¿Qué son las cooperativas prestadoras de servicios públicos?}

Las Cooperativas prestadoras de servicios públicos son organizaciones de usuarios que se agrupan para autoprestarse un servicio de interés general y autosatisfacerse una necesidad colectivamente sentida en el seno de una comunidad, mediante una empresa de propiedad conjunta y gestión democrática.

Las cooperativas objeto de estudio tuvieron lugar en Argentina por las necesidades que tenían los pobladores de las zonas periféricas de resolver los problemas comunes que afectaban las condiciones de vida. Así, los vecinos se agruparon a través de este tipo de organización para autogestionarse los servicios y, de ese modo, mejorar la condición de vida de los ciudadanos y bajar los costos de acceso a la prestación.

Estas cooperativas encuadran en la clasificación de cooperativas de consumo, donde los asociados se aglutinan con el objeto de obtener una mejor condición del servicio y a menor precio; sin embargo, la característica de este modelo cooperativo está dada por el tipo de servicio que prestan a sus propios asociados: los llamados servicios públicos. Encuadran dentro de la noción de servicio público en Argentina², la distribución domiciliaria de agua, gas, energía y el servicio de telefonía fija. Igualmente, estas cooperativas prestan en Argentina otros servicios que no encuadran en la noción de "servicios públicos» pero que son prestaciones de interés general, tales como servicios fúnebres, farmacia, enfermería, biblioteca, internet, televisión por cable, entre otros.

Las cooperativas prestadoras de servicios públicos son personas jurídicas privadas toda vez que nacen de la voluntad de un grupo de particulares-consumidores (aunque el Estado puede ser un asociado más de la cooperativa) y, en segundo lugar, su origen, funcionamiento y relación con terceros (no así con el poder concedente y con los usuarios)

2 La noción de servicio público varía de acuerdo a los contextos históricos. Hoy, en Argentina mayormente los autores comparten que el servicio público es un régimen exorbitante impuesto por el legislador y garantizado por las autoridades, a una actividad económica determinada, que tiene como finalidad el interés general y procura satisfacer necesidades individuales de importancia colectiva, cuyas características de prestación se destacan por ser de contenido económico. En especie, de manera periódica y sistemática, la prestación de servicios por parte de las cooperativas tales como educación, enfermería, funeraria, préstamos, vivienda, entre otros, no son encuadrables dentro del paraguas de la noción de servicio público. En sintonía con este tipo de noción encontramos a Pérez Hualde: "Servicios Públicos, Régimen, Regulación y Organismos de Control», en Pérez Hualde: Servicios Públicos y Organismos de Control, p. 12. Comadira: «El derecho administrativo como régimen exorbitante en el servicio público», en AA.VV: Servicio Público, Policía y Fomento, p. 22. 
están regidos por el derecho privado. Estos factores son determinantes, por sí mismos, de su condición privada, y encuadran perfectamente dentro del genérico concepto ${ }^{3}$ de sociedad que abraza la Ley General de Sociedades argentina.

Según dispone la norma, la sociedad es definida legalmente a través de los elementos que la componen: aportación para la producción e intercambio de bienes y servicios, con la finalidad de participar en los beneficios y soportar las pérdidas. Como se advierte, la mencionada ley no establece que el objeto de la sociedad comercial sea el lucro sino la participación en los beneficios, por ello es coincidente con el objeto de las cooperativas. Pero, además, mantiene importantes analogías con las sociedades, ya que su capital se divide en acciones y se le aplica supletoriamente la Ley 19.550 por expresa disposición legal.

Son empresas pertenecientes a la economía social en tanto su actividad productiva se basa en técnicas de organización específica fundamentada en los principios de solidaridad y participación, así como también en los valores de la autonomía y de la ciudadanía. ${ }^{4}$

Estas entidades actúan en base a los siguientes principios orientadores: (i) Primacía de las personas y del fin social sobre el capital, que se concreta en gestión autónoma y transparente, democrática y participativa, que lleva a priorizar la toma de decisiones más en función de las personas y sus aportaciones de trabajo y servicios prestados a la entidad o en función del fin social, que en relación con sus aportaciones al capital social; (ii) Aplicación de los resultados obtenidos de la actividad económica principalmente en función del trabajo aportado y servicio o actividad desarrollada por las socias y socios o por sus miembros y, en su caso, al fin social objeto de la entidad; (iii) Independencia respecto de los poderes públicos.

De allí que podamos concluir que las cooperativas prestadoras de servicios públicos son organizaciones nacidas al amparo de las necesidades insatisfechas de los vecinos que el Estado no concurría a satisfacer y a las que el mercado no les interesaba; son personas privadas, encuadran dentro de la noción de sociedad que abraza nuestra Ley

3 El art. 1 reza «Habrá sociedad si una o más personas en forma organizada conforme a uno de los tipos previstos en esta ley, se obligan a realizar aportes para aplicarlos a la producción o intercambio de bienes o servicios, participando de los beneficios y soportando las pérdidas».

4 Conf. Definición de la Comisión de las Comunidades Europeas, en su Comunicación al Consejo de 18 de diciembre de 1989, titulado: "Las empresas de la Economía Social y la construcción de un mercado único sin fronteras». 
General de Sociedades, a la vez que son empresas pertenecientes a la economía social y, por ello, no podemos negar sus elementos distintivos que están dados fundamentalmente por los principios y por otras características particulares, a saber: a) Primacía del hombre sobre el objeto; b) Adhesión voluntaria y abierta y control democrático; c) Autonomía e independencia de gestión en relación con entes tanto públicos como privados; d) Aplicación de los excedentes al objeto, a través de reinversión o distribución mediante retorno, previa reserva legal obligatoria; e) Presencia y preocupación por el tejido social.

Veamos entonces, en el punto siguiente, cómo se concilian los principios cooperativos con la naturaleza y las características de las cooperativas prestadoras de servicios públicos.

\section{Los principios cooperativos: su adaptación a las cooperativas prestadoras de servicios públicos y las tensiones que genera}

a) Principio de libre ingreso y adhesión voluntaria

El principio reza: «Las cooperativas son organizaciones voluntarias, abiertas a todas las personas capaces de utilizar sus servicios y dispuestas a aceptar las responsabilidades de ser socio, sin discriminación social, política, religiosa, racial o de sexo».

El principio de asociación voluntaria implica entonces que la incorporación de una persona a la cooperativa debe ser el resultado de una decisión propia de aquella, asumida en libertad y, en todo caso, resultado de un estudio, comprensión y aceptación de los valores cooperativos $^{5}$.

Ahora bien, este principio de libre ingreso y adhesión voluntaria de alguna manera no se compadece con el régimen de las cooperativas de servicios públicos, toda vez que el carácter especial del servicio que prestan, en la generalidad de los casos, es monopólico y no permite a los usuarios el acceso al mismo por otro medio.

De manera tal que cuando la organización cooperativa de usuarios es la que presta el servicio a una comunidad y este es monopólico los habitantes se encuentran forzados a asociarse porque no se encuentran con otra alternativa para gozar del servicio6.

5 Callejo: Los principios cooperativos y las cooperativas de servicios públicos, p. 19 y sig.

6 Callejo: Los principios cooperativos y las cooperativas de servicios públicos, p. 22 y sig. 
Ante estas contingencias, para que no se vulnere el principio en cuestión se presentan dos soluciones complementarias entre sí: a) la prestación a «no socios» y b) la concientización colectiva de los beneficios cooperativos.

La prestación a «no socios» está permitida por el artículo 2 inciso 10 de la Ley de Cooperativas, que establece que «las cooperativas prestan a los no asociados en las condiciones que establezca la autoridad de aplicación destinando los excedentes derivados de tales operaciones a una cuenta especial de reserva (artículo 42, último párrafo, Ley 20.337)» ${ }^{7}$.

Por lo tanto, si bien este principio se encuentra en tensión frente a este modelo de gestión, ya que la mayoría de los usuarios son asociados y de algún modo se ven inducidos a asociarse, la posibilidad de recibir el servicio público sin necesidad de asociarse permite a las cooperativas ajustarse al cumplimiento del principio de libre ingreso y adhesión voluntaria reconocido por la Alianza Cooperativa Internacional.

\section{b) Principio de control democrático}

El principio es desarrollado en los siguientes términos: "Las cooperativas son organizaciones gestionadas democráticamente por sus asociados, los cuales participan activamente en la fijación de sus políticas y en la toma de decisiones. Los hombres y mujeres elegidos para representar y gestionar las cooperativas son responsables ante los socios. En las cooperativas de primer grado, los socios tienen iguales derechos de voto (un socio, un voto), y las cooperativas de otros grados están también organizadas de forma democrática» ${ }^{8}$.

De los términos del documento se induce que "democracia» incluye consideraciones sobre derechos y responsabilidades, pero significa también algo más: significa promover el espíritu de la democracia en las cooperativas 9 .

En el caso de las cooperativas prestadoras de servicios públicos, las asambleas son generalmente indirectas en tanto el volumen de asociados es equivalente a un integrante por cada hogar de la comunidad en la cual se desarrolla y presta el servicio la cooperativa. Las asambleas in-

7 Cracogna: Problemas actuales del Derecho Cooperativo, p. 79.

8 «Declaración sobre la identidad cooperativa», ACl, 1995.

9 Punto 45 del «Documento de Referencia acerca de la Declaración sobre la Identidad Cooperativa», $\mathrm{ACl}, 1995$. 
directas permiten elegir a los delegados que conformarán el órgano de gobierno.

A pesar de que existen controversias en cuanto a si las asambleas indirectas respetan el principio en análisis, nosotros entendemos que el principio de control democrático es perfectamente compatible con las cooperativas de servicios públicos y con las asambleas indirectas que deben llevarse a cabo en este tipo de organizaciones, donde no se concibe una democracia directa por el volumen de asociados.

En este sentido, nuestra legislación nacional se hace eco de la democracia indirecta y prevé obligatoriamente la constitución de asambleas de delegados cuando el número de asociados supere los 5.000 (artículo 50, Ley 20.337); del mismo modo, lo hacía la vieja Ley 11.388, con la salvedad de que el límite era de 10.000 asociados.

De tal modo que no encontramos afectación alguna al principio de control democrático por el hecho de que los asociados elijan democráticamente delegados asambleístas que conformaran el órgano de gobierno de la cooperativa y que elegirá a los administradores.

Sin embargo, sí advertimos que estas cooperativas sufren un destacado debilitamiento en el funcionamiento democrático interno. Ello obedece a la falta de participación de los socios; la manipulación de los mecanismos electorales por parte de los administradores; el control de la organización por aquellos que la dirigen y disminución de la influencia de los asociados; la preponderancia de estructuras burocráticas y concentración del poder en los dirigentes; la carencia de oposición y la falta de información a los asociados, permitiendo ello que las conducciones se mantengan por años en la administración de estas entidades.

Las debilidades señaladas ponen en crisis el demos y la representación de los administradores y miembros de los demás órganos, afectando a su vez la propia integración asociativa.

En este sentido, advertimos que sólo un promedio del 10\% de los asociados a las cooperativas prestadoras de servicios públicos concurre a emitir su voto y, a su vez, muy pocos se involucran en el control de la administración y en la vida de la cooperativa.

Por otra parte, la afectación del mencionado principio también se advierte en las normas estatutarias que en muchos casos no contemplan la incorporación de las minorías. Como la Ley de Cooperativas no exige tal recaudo, si el contrato social no lo incorpora quien resulta vencedor en las elecciones ocupa la totalidad de los cargos, tanto de delegados como de consejeros a cubrir, sin que ello permita la pluralidad de voces y el control de gestión por parte de la oposición. Ello genera un daño irremediable al principio en análisis. 
En lo que refiere a las asambleas directas, cuando los asociados no superan el máximo de 5.000, allí también se advierte en la práctica una clara afectación al principio de control democrático, toda vez que, en general, los administradores difícilmente se recambian porque éstos, junto al grupo de poder, utilizan todo tipo de maniobra para imponerse en las asambleas, tales como control de ingreso al recinto, estrategias e ingeniería electoral que propicia la permanencia de quienes lideran.

Siguiendo con las demás cuestiones que afectan el principio democrático es importante poner el foco en la conducta de los administradores y grupos de control que omiten recrear una cultura de integración asociativa.

Como venimos diciendo, son pocos los asociados que se interesan y se involucran con la cooperativa, pero también son pocos administradores los comprometidos con la promoción de la participación.

Consecuencia del perfil de los procesos que viven estas cooperativas y de las conductas usuales de los administradores que las dirigen, también encontramos que es difícil la consolidación de una oposición. A su vez, al no recrearse la integración asociativa ni la convocatoria a los asociados, difícilmente encontraremos nuevos liderazgos.

Lo que queremos mostrar con los hechos reseñados, que afectan el principio del control democrático, es que de ningún modo hay una afectación de este control porque la elección sea indirecta, sino que la misma proviene de la baja participación de los asociados y de las prácticas de muchos administradores para mantenerse en el ejercicio de la gestión.

\section{c) Principio de participación económica}

El principio en cuestión señala que "Los socios contribuyen equitativamente a la formación del capital de la cooperativa y lo gestionan democráticamente. Por lo general, al menos una parte de este capital es propiedad común de la cooperativa. Los socios suelen recibir una compensación limitada, si acaso alguna, sobre el capital suscrito como condición para asociarse. Destinan los excedentes a todos o algunos de los siguientes fines: el desarrollo de la cooperativa, posiblemente mediante la constitución de reservas de las cuales una parte al menos debe ser indivisible; la distribución a los socios en proporción a sus operaciones con la cooperativa; y el apoyo a otras actividades aprobadas por los socios».

En punto a las formas de contribución de los socios para el financiamiento de las cooperativas y su eventual compensación, el docu- 
mento de la $\mathrm{ACl}$ elaborado en Manchester distingue entre el capital individual de cada socio y lo que sería un capital colectivo, es decir, las reservas provenientes de la actividad de la organización ${ }^{10}$.

Sobre el capital individual diremos que el capital obligatorio lo «constituye el aporte equitativo primario reflejado en la cuota de pertenencia para gozar de los derechos de uso del servicio y participación democrática en la actividad social», como así también las nuevas aportaciones al capital, señalándose en el documento que "sólo en raras ocasiones esa cuota o aporte del asociado produce algún interés» ${ }^{11}$.

Por su parte, los socios también pueden realizar un aporte de capital voluntario, que como su nombre lo indica no es exigido para ser miembro de la misma y consiste en un desembolso adicional. El aporte voluntario no se encuentra previsto en la Ley de Cooperativas argentina (Ley 20.337), aunque frente a la anomia legal la Autoridad de aplicación reconoció, por medio de las resoluciones del INAES 349/95, 593/99 y 1.966/95, la posibilidad de hacer aportes complementarios mediante la emisión de títulos cooperativos de capitalización.

Ahora bien, focalizando en el plano de las cooperativas de servicios públicos advertimos que, en Argentina, este tipo de entidades no contemplan habitualmente el pago de intereses sobre el capital. Tampoco es habitual que, sobre la base de las Resoluciones de la Autoridad de aplicación referenciadas precedentemente, dispongan sobre aportes voluntarios.

Sí vemos que, en el marco de la normativa reinante en la Argentina (artículo 27 Ley 20.337), este tipo de cooperativas resuelven con frecuencia - mediante Asamblea - recurrentes aumentos de capital que lógicamente son aplicados al uso que dicha Asamblea disponga. Esta herramienta es muy utilizada por ser necesaria para sostener el capital que permite hacer frente a las inversiones que requiere el servicio, máxime en épocas recientes donde la tarifa y la inflación reinante no permitían destinar fondos para inversiones.

\section{d) Principio de autonomía e independencia}

La ACl ha formulado en su congreso de Manchester de 1995 el cuarto principio cooperativo bajo los siguientes términos: «Las coope-

10 Callejo: Los principios cooperativos y las cooperativas de servicios públicos, p. 39.

11 Punto 50, primer párrafo, del «Documento de Referencia acerca de la Declaración sobre la Identidad Cooperativa», ACl, 1995. 
rativas son organizaciones autónomas de autoayuda gestionadas por sus socios. Si intervienen en acuerdos con otras organizaciones, incluidos los gobiernos, o captan capital de fuentes externas, lo hacen en términos que aseguran el control democrático por parte de los socios y mantienen su autonomía cooperativa».

El principio destaca que no se puede afectar en ningún caso (incluida la captación del capital de fuente externa) el control democrático por parte de los socios. Y a diferencia de otras legislaciones como la española, Argentina no permite otros socios que aquellos a quienes la cooperativa está abierta, es decir, las personas capaces de utilizar sus servicios. No hay posibilidad de internalizar con ese status a otras personas ni siquiera poniéndole límites a sus derechos políticos o económicos dentro de la cooperativa ${ }^{12}$.

Ello no significa que las cooperativas no puedan ser socias en otras sociedades comerciales. En efecto, el artículo 5 de la Ley de Cooperativas argentina admite que las cooperativas «pueden asociarse con personas de otro carácter jurídico a condición de que sea conveniente para su objeto social y que no desvirtúen su propósito de servicio».

En definitiva, la Alianza Cooperativa Internacional pretende condicionar las asociaciones de las cooperativas con otras sociedades comerciales y con el Estado, para que en esa vinculación no se afecte la autonomía de éstas, ni el control democrático por parte de los socios de la propia cooperativa.

Este punto es crucial para las cooperativas prestadoras de servicios públicos porque, justamente por el tipo de actividad, sus vinculaciones con el Estado son esenciales para la prestación del servicio y de ello se derivan muchas situaciones de interferencia en la autonomía de las cooperativas.

En este sentido, cabe advertir sobre los potenciales efectos nocivos que acarrea para este principio la intervención del Estado en la fijación de las tarifas de los servicios públicos prestados por cooperativas.

Por otra parte, se critica que, en el caso de las cooperativas prestadoras de servicio público, en líneas generales sus dirigentes guardan a menudo una estrecha relación con los gobiernos de turno, sin que exista en los socios y la comunidad información clara sobre este punto. Esto también puede ser relacionado con el principio de neutralidad política y religiosa.

Somos conscientes de que la mixtura entre la política y las cooperativas - lógicamente con mayor grado en las de servicios públicos- es

12 Callejo: Los principios cooperativos y las cooperativas de servicios públicos, p. 51. 
un hecho inevitable ${ }^{13}$, pero lo que se intenta superar con este principio es que los administradores limiten el libre desarrollo cooperativo con decisiones que condicionen la libertad y democracia interna y que esto provoque perjuicios al interés social.

Hoy en día, se advierte más frecuentemente en la práctica, que estas organizaciones están siendo objeto de aprovechamiento por parte dirigentes políticos que utilizan a las cooperativas con fines clientelares, generando así una clara tensión del principio en análisis.

Así las cosas, es habitual encontrar que las cooperativas prestadoras de servicios públicos son víctimas de los favores que deben los administradores que accedieron al cargo. Como así también es habitual que estas entidades sean prisioneras de las negociaciones que hacen los administradores con el poder concedente o regulador para obtener, por ejemplo, aumento de tarifa en especial en épocas inflacionarias como da cuenta la realidad argentina de los últimos años.

De tal manera que superar la injerencia de la política $-y$ de la política partidaria- en la administración de estas cooperativas, no resulta simple pero si limitamos la exposición de las cooperativas a reclamar constantes reajustes de tarifa y permitimos la incorporación de otros ítems a la factura de servicio, como por ejemplo el aporte de capitalización, entre otros, cuestiones que trataremos in extenso en otro apartado, sumado a una mayor formación de los administradores en lo relativo a la necesidad y la importancia de mantener la independencia de la institución, se resguardará más eficazmente el principio de autonomía e independencia, como también el interés social.

\section{e) Principio de educación, capacitación e información}

Surge del Congreso de Manchester que el principio en análisis ha sido levemente modificado y que ha quedado reformulado de la siguiente manera: «Las cooperativas brindan educación y capacitación a

13 Ya lo ha expresado Jacobo Amar hace más de 40 años, «las cooperativas HACEN política. Lo vienen haciendo desde antes que tomaran forma concreta con la histórica tienda de Rochdale en la calle del Sapo, en las propias especulaciones teóricas de los precursores del cooperativismo y aun en sus ensayos prácticos (...) En el trasfondo de las ideas de estos teóricos y de muchos que siguieron sus enseñanzas y fueron abonando la doctrina cooperativista, anidó la esperanza y aun el objeto político de alcanzar por vía del desarrollo del movimiento y durante sucesivas transformaciones sociales, el ideal de la sociedad cooperativista». Amar: Politica y cooperativas, p. 21 y ss. 
sus socios, representantes elegidos, administradores y empleados, de manera que puedan contribuir efectivamente al desarrollo de ellas. Informan al público en general, particularmente a los jóvenes y a los líderes de opinión, acerca de la naturaleza y los beneficios de la cooperación».

Lo que busca el documento transcrito es promover la instrucción y la comprensión del fenómeno cooperativo, y también el contenido humanista del movimiento cooperativo.

La educación ${ }^{14}$ y la capacitación ${ }^{15}$ de los actores de una cooperativa permite también un mayor y mejor cumplimiento del resto de los principios. Así, vemos que, dotado de amplios conocimientos, un cuerpo de socios puede ejercer exitosamente el control democrático, defender con pericia la autonomía de la cooperativa, garantizar plenamente la participación económica y la calidad de los servicios, etc.

Frente a las implicancias que ha tenido la postmodernidad en las sociedades, este movimiento solidario y humanista por excelencia debe ser difundido para que desde el entendimiento pueda seguir consolidándose en esta sociedad, donde mensajes de comunión y solidaridad resultan tan escasos.

Por último, cabe agregar que las cooperativas de servicios públicos están en condiciones de hacer mucho por la efectividad del principio a partir de su privilegiada posición comunitaria ${ }^{16}$.

Hoy en día, el gran desafío que enfrentan quienes dirigen y se encuentran enrolados en el cooperativismo es cómo trasladar la pasión por este tipo de organizaciones a las generaciones venideras. El problema radica en que la realidad basada en la experiencia empírica, refleja que quienes encabezan las cooperativas se mantienen celosamente en la gestión por décadas y no forman ni dan espacios a los más jóvenes.

Se suma a ello la propia actividad que explota la cooperativa de servicios públicos, que es obviamente sensible para los ciudadanos y que muchas veces la comunidad actual, en especial los más jóvenes, que no ha participado del inicio y desarrollo de la misma, no valora, ni logra diferenciarlas respecto de las empresas de capital.

14 Punto 57, 1. er párr., del «Documento de Referencia acerca de la Declaración sobre la Identidad Cooperativa», ACl, 1995.

15 Punto 57, 1. er párr., del «Documento de Referencia acerca de la Declaración sobre la Identidad Cooperativa», ACl, 1995.

16 Callejo: Los principios cooperativos y las cooperativas de servicios públicos, p. 67. 


\section{f) Principio de cooperación entre cooperativas}

El principio reza "Las cooperativas sirven más efectivamente a sus socios y fortalecen el movimiento cooperativo trabajando mancomunadamente a través de estructuras locales, nacionales, regionales e internacionales» ${ }^{17}$.

En el documento de Manchester la convocatoria a la cooperación entre cooperativas está seccionada en dos frentes: (i) en cuanto a lo funcional y operacional, y (ii) en cuanto al aspecto institucional y representativo.

En lo que respecta al primer punto dice el documento que, para lograr los beneficios de las organizaciones de gran escala, manteniendo simultáneamente las ventajas del compromiso y propiedad local, deben actuar mediante una colaboración práctica y rigurosa. Así, en todo el mundo las cooperativas deben identificar nuevos mercados para abordarlos conjuntamente.

Por otro lado, esto también significa un llamamiento para que las cooperativas no restrinjan las aspiraciones de integración al mero interés de la rama de la actividad que explotan. De este modo se exhorta a que conformen confederaciones con la finalidad de agruparse para enriquecerse y beneficiarse mutuamente con la integración de las actividades.

En definitiva, el pasaje transcrito del documento exhorta a las cooperativas a unirse aun cuando no tengan el mismo tipo de actividad, con el objeto de construir una posición fuerte ante cualquier otra institución, máxime a escala mundial y a los efectos de promover los principios cooperativos, más allá de procurar ventajas materiales.

En referencia a esta última cuestión, en Argentina las federaciones de cooperativas prestadoras de servicios públicos han sido prolíferas. Sin embargo, la cooperación entre cooperativas se da entre aquellas que se dedican a una misma rama.

Ejemplo de ello es la Federación Argentina de Cooperativas de Electricidad (FACE) que data del año 1939 y es una de las integraciones supra organizaciones más destacada en nuestro país.

La necesidad de reunirse bajo la figura de federaciones se ha dado con mayor intensidad, sobre todo, en los ámbitos locales o provinciales, entre varias cooperativas de servicios públicos de una misma acti-

17 Punto 58, 1.er párr., del «Documento de Referencia acerca de la Declaración sobre la Identidad Cooperativa», ACl, 1995. 
vidad, que luego, a su vez, confluyen con mayor identidad y peso ante una Federación Nacional.

Indudablemente, este proceso de integración es sumamente trascendente para el movimiento cooperativo, porque dicha unión permite a las cooperativas negociar con los actores privados, así también con el Estado, en condiciones más ventajosas.

\section{g) Principio de la preocupación por la comunidad}

Este principio vio la luz por primera vez en el Congreso de Manchester de 1995, como consecuencia de la creciente y global toma de conciencia sobre la preservación del ambiente y los recursos que, en definitiva, son patrimonio de toda la humanidad.

Así, dice: «Las cooperativas trabajan para conseguir el desarrollo sostenible de sus comunidades mediante políticas aprobadas por sus socios».

Sin dudas, este nuevo principio se hace eco de los contemporáneos esfuerzos de la ONU por elaborar y advertir sobre los peligros de la actividad humana en el equilibrio medioambiental y en la explotación de los recursos, tales como el «Informe Brundland» de 1987, y la «Declaración de Río sobre el Medio Ambiente y el Desarrollo»18, de 1992.

Así, corresponde preguntarse ¿cómo juega este principio en relación con las cooperativas de servicios públicos? Para responder este interrogante, en primer lugar, hay que decir que conforma la esencia de la cooperativa de servicios públicos la satisfacción de necesidades individuales de alcance colectivo (servicio comunitario). Como ya fuera dicho en su oportunidad, la nota distintiva de esta clase de cooperativas es el objeto, brindar un servicio de interés general, por lo que este principio está ínsito en la naturaleza de su prestación.

Con respecto a la protección del medioambiente y al desarrollo sustentable de los recursos, las cooperativas prestadoras de servicios públicos tienen el compromiso de velar por la tranquilidad de la comunidad y por el equilibrio medioambiental, tanto en la explotación del servicio como en cualquier otro tipo de aporte que haga al mejoramiento comunitario, en cuestiones ajenas a su cometido.

18 Así, en el Principio $3 .^{\circ}$ se establece: «El derecho al desarrollo debe ejercerse en forma tal que responda equitativamente a las necesidades de desarrollo y ambientales de las generaciones presentes y futuras». 


\section{Desarrollo del cooperativismo de servicio público en Argentina}

El destacado desarrollo en Argentina del cooperativismo de servicios públicos tiene origen en el año 1926, en la ciudad de Punta Alta, provincia de Buenos Aires. Esta cooperativa, que comenzó su operatoria en octubre de 1927, decidió cobrar la mitad de la tarifa que aplicaba la empresa de capital que hasta entonces prestaba el servicio, suprimiendo además los pagos que se exigían por consumo mínimo y alquiler de medidor. El rápido desarrollo de la cooperativa generó la reacción de la empresa prestataria y contando con el acompañamiento del Estado provincial se le quitó la personería a la cooperativa en 1929.

Sin embargo, la experiencia alentadora de Punta Alta sirvió como modelo y estímulo para la fundación de numerosas entidades similares, entre ellas las de San Martín (Buenos Aires, 1930), Río Tercero (Córdoba, 1933), Bahía Blanca y Zarate (Buenos Aires, 1934), y otras en las provincias de Chubut, Santa Fe y La Pampa.

Actualmente funcionan 800 cooperativas prestadoras de servicios públicos, que brindan electricidad, gas, teléfono y agua corriente, entre otros, a más de 600 ciudades del interior del país. Algunas son uniactivas, ya que brindan un solo servicio, y otras son multiactivas por brindar varios. La gran mayoría presta varios servicios públicos a la vez y, por ende, están a distintos poderes regulatorios y de contralor.

Las estadísticas demuestran que el $60 \%$ de las cooperativas prestadoras de servicios públicos provee agua, el 53,1\% provee electricidad, el $33,3 \%$ es prestadora de telefonía, el $13,1 \%$ provee cloacas, el 7,3\% presta servicio de gas y el $6,4 \%$, servicios varios.

Las provincias argentinas que lideran el movimiento cooperativo de servicio público son las provincias de Buenos Aires, Santa Fe y Córdoba. Por su parte, las cooperativas patagónicas como la de Bariloche, Comodoro Rivadavia y Neuquén tienen la mayor cantidad de asociados, convirtiéndose en las cooperativas más pujantes del país.

La experiencia internacional sobre constitución de este tipo cooperativo, en especial en servicios eléctricos tiene antecedentes en los Estados Unidos de Norteamérica en especial en las zonas rurales ${ }^{19}$. En La-

19 Frediani, Branda, Sesin, Ingaramo: Transferencia de Servicios Públicos a Empresas Cooperativas, p. 16. Serían 900 las cooperativas eléctricas que abastecen energía a 42 millones de personas en USA (www.nreca.coop). 
tinoamérica encontramos un importe desarrollo en Bolivia, Costa Rica, entre otros 20 .

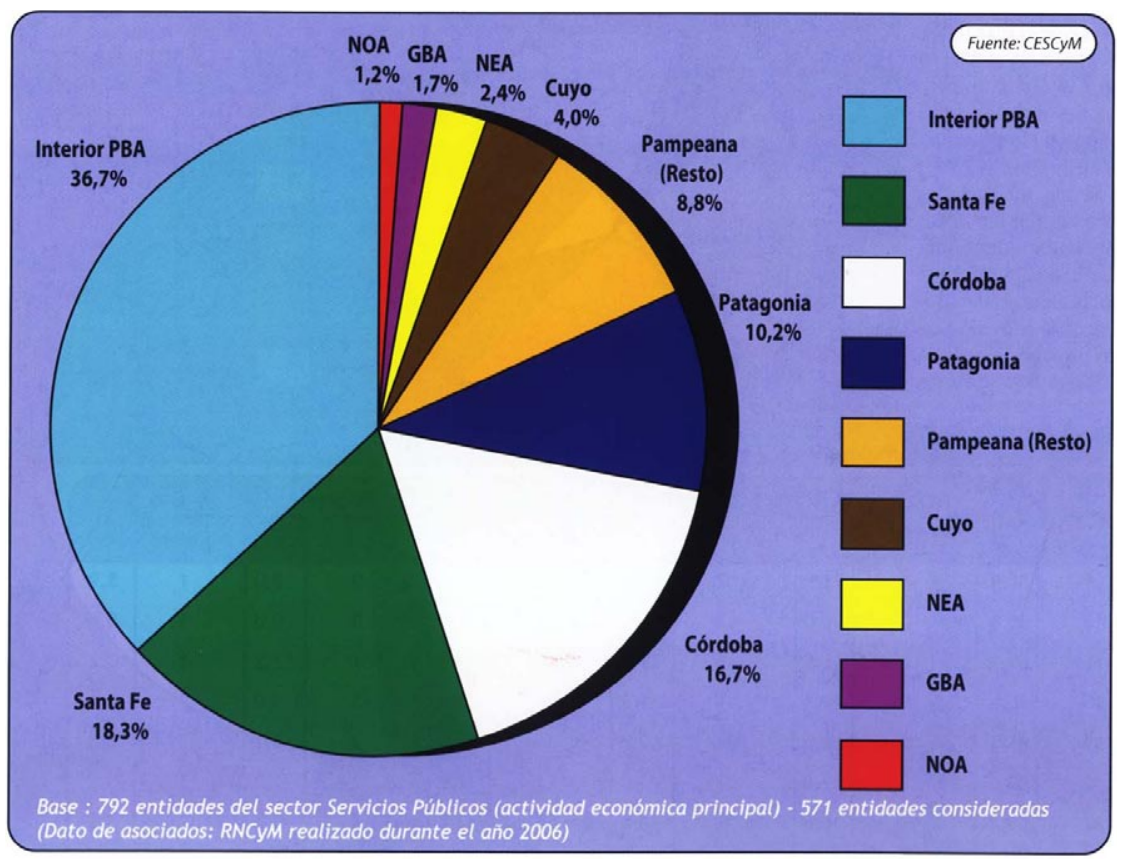

Entidades cooperativas prestadoras de servicios públicos por región

\section{Contribución social del cooperativismo de servicio público}

Las cooperativas de servicios son organizaciones tan enraizadas en las comunidades del interior de la República Argentina que hacen a la propia identidad de los pueblos y ciudades donde están insertas.

20 En el marco de la XVII Conferencia Regional de la ACl-Américas se decidió la conformación de una red de cooperativas de servicios públicos con el objetivo de fortalecer las relaciones entre las cooperativas de América, mediante el intercambio de información y acciones, para potenciar el desarrollo y crecimiento del sector cooperativo en sí mismo y en nuevos emprendimientos. Dicha red está conformada por representantes de Reino Unido, USA, Bélgica, Costa Rica, Argentina, México, Bolivia, Paraguay, Canadá. Mayor información se puede encontrar en http://www.aciamericas.coop/Red-de-cooperativas-de-servicios. 
Son y han sido pilares fundamentales sobre los que se sustenta la economía regional y la sustentabilidad de nuestros pueblos.

La contribución social no se ciñe solo a la prestación del servicio a un precio más económico, sino que son agentes de la cohesión social y expresiones de una solidaridad más cercana. Así, con acierto se dice que "en tiempos de crisis, han sido también las organizaciones cooperativas las que han actuado como verdaderos colchones sociales, sintiéndose parte de un movimiento mucho más grande que ahora llamamos Economía Social y Solidaria. Sobre todo, entendiendo que solamente es posible el desarrollo individual del ser humano cuando se forma parte del conjunto de una sociedad que cultiva valores y principios democráticos y equitativos».

Los pioneros de estas empresas nunca imaginaron el crecimiento de estas organizaciones, crecimiento que acompaño el aumento de la densidad demográfica de estos sectores del interior profundo de la argentina.

Las cooperativas prestadoras de servicios públicos han cumplido y siguen cumpliendo una importante función social. Por ser espacios democráticos de participación, han contribuido a la organización de los territorios donde están insertas, esto es: en la distribución espacial de las actividades urbanas y rurales, en las fuentes de energía utilizadas, las cadenas de valor prioritarias, la constitución del entramado productivo, la organización del hábitat, su impacto en el medio ambiente y los mecanismos para garantizar el acceso de toda la población a los bienes y servicios que permitan un buen vivir ${ }^{21}$.

Además, por estar representadas por los mismos usuarios, a estas organizaciones les ha sido más fácil identificar las nuevas demandas sociales que se fueron imponiendo en las sociedades modernas. Así, empezaron en muchos casos generando electricidad o proveyendo gas o agua potable. No obstante, después fueron ampliando sus servicios a otras prestaciones que, si bien no son encuadrables en el concepto de servicio público, fueron y son muy importantes para el desarrollo de las sociedades, tal es el caso de la telefonía móvil, televisión por cable, Internet, enfermería, sepelios, entre otros.

Indiscutiblemente, el desarrollo del cooperativismo de servicio público ha servido de vector del crecimiento con equidad de muchas comunidades de nuestro país y ha ayudado a fomentar el arraigo de las personas en su lugar de origen, dando trabajo a su gente.

Esta matriz alternativa de prestación de servicios públicos, que tuvo origen en poblaciones o ciudades embrionarias o de poca cantidad de

21 Guarco: El cooperativismo argentino, p. 112. 
habitantes en Argentina y que sería difícil desarrollarse en la actualidad por el volumen de las ciudades, ha logrado sobrevivir hasta nuestros días y depende de la adaptación de estas organizaciones a los nuevos retos que la tecnología y la vida posmoderna imponga que puedan seguir siendo una realidad eficaz para resolver las necesidades de los vecinos.

\section{Principales desafíos que enfrenta este modelo de gestión en la posmodernidad}

1. La necesidad de que se reconozca en los contratos de concesión y normas regulatorias la naturaleza de la entidad con medidas eficaces que garanticen la ecuación económica financiera del servicio

De los marcos regulatorios nacionales en materia de servicios de gas, electricidad y telecomunicaciones no se encuentran previstos regímenes especiales que encuentren como eje la naturaleza cooperativa del prestador. En lo que hace a los servicios públicos de jurisdicción nacional, vemos que en el régimen de distribución de gas no existe distinción alguna cuya variable sea la naturaleza cooperativa del prestador22. Es más, las cooperativas que se desempeñan abasteciendo de gas natural a ciudades y pueblos son «sujetos activos de la industria del gas natural» y, como tales, están alcanzados por el Marco Regulatorio Nacional y obligados a cumplir con los reglamentos y disposiciones del Ente Nacional Regulador del Gas.

La misma situación se verifica en materia de telecomunicaciones, no obstante se reconoce expresamente la función esencial de las cooperativas en el desarrollo regional de la telefonía y, en consecuencia, se les concedió por ello cierta prerrogativa de exclusividad zonal ${ }^{23}$ e intangibilidad en el proceso de privatización que sobrevino a fines de la dé-

22 Se analizaron la Ley Nacional n. ${ }^{\circ} 24.076$ y su Decreto Reglamentario n. ${ }^{\circ}$ 1.738/92; Decreto n. ${ }^{\circ} 2.255 / 92$ y sus anexos; Resolución ENARGAS n. ${ }^{\circ} 35 / 93$ sobre subdistribución de gas por redes, entre otras normas.

23 El artículo 14 de la Ley Nacional N. ${ }^{\circ} 19.798$ dice: «En ningún caso se otorgarán autorizaciones o permisos de explotación que importen el establecimiento de exclusividades o monopolios incompatibles con la soberanía, desarrollo y seguridad nacional. La existencia de tales situaciones faculta a la autoridad de aplicación para disponer la caducidad de las respectivas autorizaciones o permisos. Se autorizará o permitirá la instalación de entes telefónicos privados (cooperativas) cuyo fomento satisfaga requerimientos de desarrollo regional, con las limitaciones que determina el párrafo precedente y la reglamentación de esta ley». 
cada de los ochenta ${ }^{24}$. Sin embargo, no se contempla diferenciación regulatoria para aquellas cooperativas.

Del mismo modo, recorriendo la legislación local de las principales provincias con actividad cooperativista en el rubro de la distribución del servicio de energía (tomamos los casos testigo de la Provincia de Buenos Aires, Córdoba, La Pampa y Neuquén) observamos que no existen diferencias sustantivas en el tratamiento regulatorio conforme a la distinta naturaleza jurídica que pueden presentar los potenciales prestatarios de los servicios públicos de jurisdicción local.

El marco regulatorio de la Provincia de Buenos Aires jerarquiza y privilegia al ente cooperativo como prestador esencial del servicio de distribución ${ }^{25}$.

Por otro lado, se hace un reconocimiento expreso de la norma a la inclusión de otros cargos distintos al suministro de energía eléctrica en la facturación, resaltando entre sus previsiones al caso cooperativo ${ }^{26}$. Aunque en el año 2018 se procuró excluir cualquier ítem

24 El Decreto n. ${ }^{\circ} 731 / 89$ dispuso la privatización del Ente Nacional de Telecomunicaciones y la creación de dos áreas de red telefónica comprensivas de la totalidad del territorio nacional, a ser adjudicadas a dos sociedades anónimas (art. 2). No obstante, el art. 4 excluye de tal régimen a las cooperativas telefónicas, al prescribir que «Las sociedades cooperativas que actualmente prestan servicios telefónicos mantendrán sus derechos sin perjuicio de su eventual participación en el capital de la licenciataria a quien se le adjudique la región que corresponda a su ubicación geográfica».

25 El art. 20 de la Ley n. ${ }^{\circ} 11.769$ (reglamentado por Decreto Provincial n. ${ }^{\circ} 2.479$ ), en su parte pertinente prescribe que "Los generadores y los concesionarios de servicios públicos de distribución de electricidad deberán organizarse como sociedades anónimas, admitiéndose para el caso de servicios públicos de distribución, que sus titulares sean cooperativas integradas por los usuarios de esos servicios públicos, o sociedades de economía mixta.

"La Provincia de Buenos Aires reconoce especialmente entre los Distribuidores concesionarios del servicio público de electricidad a las entidades Cooperativas, en virtud de su naturaleza y los antecedentes históricos en la constitución y prestación del servicio eléctrico.

«En tal sentido, es propósito de esta Ley alentar el desarrollo de estas entidades y, especialmente las que atienden zonas rurales de la Provincia, en consideración a que persiguen un fin comunitario.

«En tal marco, toda legislación y reglamentación que se dicte para regular el servicio eléctrico deberá contemplar adecuadamente la existencia y normal continuidad de dichas entidades cooperativas».

${ }^{26}$ Tal es así que el art. 78 del actual marco regulatorio creado por Ley 11.769 dice: «Podrán incluirse en las facturas conceptos ajenos a la prestación del servicio público, cuando tal procedimiento hubiera sido expresa e individualmente autorizado por el usuario y aprobado por el Organismo de Control y siempre que se permita el pago por separado de los importes debidos exclusivamente a la prestación del suministro eléctrico». 
ajeno a la tarifa del servicio principal a consecuencia de la Resolución del INAES 3443/18 que lo dispuso de manera inconstitucional y avasallando las competencias provinciales ${ }^{27}$.

De forma menos gravitante, la legislación en materia de energía eléctrica de la Provincia de Córdoba contiene algunas notas distintivas a favor del sector cooperativo. En este sentido, se habilita a las cooperativas prestadoras del servicio de distribución de energía a brindar otros servicios, siempre que los valores sean desagregados y discrimina$\operatorname{dos}^{28}$.

A tono con su normativa constitucional, el marco regulatorio del servicio público de energía eléctrica de la Provincia de La Pampa prevé un trato deferente a favor de las cooperativas, principalmente en materia de selección de los sujetos prestadores del servicio ${ }^{29}$. En cuanto a los restantes objetos de regulación, no se presentan distinciones de importancia ${ }^{30}$, más allá de cierta regulación de cargos y subsidios para infraestructuras dispuesta por la autoridad de aplicación y control local ${ }^{31}$.

«En el caso cooperativo, la aprobación mencionada en el párrafo anterior, deberá responder a la normativa específica del Órgano local competente en la materia». A lo que añade la reglamentación: "En los casos de entidades cooperativas, se requerirá la aprobación por parte del OCEBA, sin perjuicio de la que corresponda al organismo fiscalizador con competencia en la materia, de conformidad a los términos de la Ley de Cooperativas n. ${ }^{\circ} 20.337 »$.

27 La resolución 3443/2018 del INAES intentaba limitar el poder de policía de las provincias y/o en su caso de los municipios, cuando las provincias lo han delegado a estos pero exorbitaba las facultades del propio organismo, como así también las atribuciones que surgen de ley de cooperativas, que según art. 1 dispone «Ejercer en el ámbito nacional las funciones que le competen al Estado Nacional como autoridad de aplicación del régimen legal que regula el funcionamiento de las Asociaciones Mutuales y las Cooperativas establecido por las Leyes N. ${ }^{\circ} 20.321$ y 20.337 , sus modificatorias y complementarias y por las normas que en el futuro se dicten al respecto». Dicho artículo no le permite involucrarse en materia regulatoria del servicio público, sino solo del funcionamiento de las cooperativas.

28 Art. 32, 2 do párr. de la Ley Provincial N. ${ }^{\circ} 8.837$.

29 Ley Provincial n. ${ }^{\circ} 1.101$, arts. 4 inc. a) y 21 inc. h). El art. 4 a) dice: «En cumplimiento de lo dispuesto en el artículo anterior, el Poder Ejecutivo propenderá a que las necesidades de energía eléctrica sean satisfechas por: a) Municipios, comisiones de fomento, cooperativas de primero o segundo grado, consorcios de vecinos o sociedades de economía mixta o sociedades anónimas donde el Estado posea la mayoría del capital accionario». El art. 21 dice: "Es de la competencia específica de la Administración Provincial de Energía: h) fomentar la creación de sociedades cooperativas y de asociaciones entre éstas y el Estado».

30 Por ejemplo, en materia tarifaria la Ley Provincial n. ${ }^{\circ} 1.451$ adhiere a las pautas generales del régimen tarifario nacional.

31 Ver al respecto las Disposiciones n. ${ }^{\circ}$ 23/2013 y 34/2013 de la Administración Provincial de Energía de La Pampa. 
Por último, la Provincia del Neuquén, a pesar de contar con un texto constitucional promisorio en materia cooperativa, lejos está de propender a un régimen de la energía eléctrica que privilegie, proteja o fomente al cooperativismo.

Sin embargo, se destaca que en materia eléctrica el órgano de contralor del servicio en la ciudad de Neuquén habilita a que la empresa prestataria incorpore en la factura tanto el ítem de aporte de capital, como otros servicios que presta la cooperativa (por ejemplo, Servicios fúnebres) ${ }^{32}$.

En lo que refiere al servicio de agua y disposición de efluvios cloacales no se presentan distinciones reglamentarias en relación con la prestación por parte de cooperativas en las provincias de La Pampa33, Córdoba ${ }^{34}$ y Neuquén ${ }^{35}$.

Como podemos ver, en materia de servicios públicos cooperativos la normativa, tanto a nivel nacional como a nivel provincial, es insuficiente y descoordinada.

En lo que respecta a la naturaleza cooperativista,esta verdadera anomia presente en la regulación de los servicios públicos nos permite afirmar que no hay distinciones regulatorias, ni contratos de concesión a la medida.

32 Conforme reciente Ordenanza n. ${ }^{\circ} 14.178$.

33 Ver al respecto: Ley n. 607 (Código de Aguas); Ley n. ${ }^{\circ} 773$ (Creación de la Administración Provincial del Agua); Ley n. ${ }^{\circ} 1.027$ (Régimen de conservación y uso de Agua Potable); Ley n. ${ }^{\circ} 1.476$ (Régimen de servidumbre administrativa de ductos). Según el Decreto Provincial n. ${ }^{\circ}$ 193/81 (reglamentario de la mentada Ley n. ${ }^{\circ} 1.027$ ), "Serán prestadores de los servicios de Agua Potable, en su caso, los Municipios, las Comisiones de Fomento, y excepcionalmente el Estado Provincial. Los Organismos e Instituciones mencionadas, serán responsables de la Administración, operación y mantenimiento de los servicios que podrán conceder a Entes Cooperativas o a particulares» (art. 2), siendo la Administración Provincial del Agua (ente público provincial) el organismo regulador en la materia (art. 7).

$34 \mathrm{Si}$ bien se reconoce expresamente la presencia de cooperativas prestadoras del servicio de aguas y desagües, el Anexo del Decreto n. ${ }^{\circ}$ 529/94 (Marco Regulador para la Prestación de Servicios Públicos de Agua Potable y Desagües Cloacales en la Provincia de Córdoba) sólo trata en disposición transitoria (art. 61) las pautas de adaptación de los entes cooperativos al nuevo marco regulatorio, siendo aquel marco regulador de aplicación plena e irrestricta para todos los prestadores sin distinción.

${ }^{35}$ La prestación del servicio de agua potable y tratamiento de aguas servidas se encuentra principalmente a cargo del Ente Provincial de Agua y Saneamiento (ente público provincial), sin perjuicio de lo cual existen en pequeñas localidades del interior de la provincia cooperativas que tienen a su cargo la provisión de agua. Ver http://www.epas. gov.ar/pgs/institucional_que_es_el_epas.html

En materia regulatoria no hay regímenes especiales para las cooperativas; ver al respecto Ley Provincial n. ${ }^{\circ} 899$ (Código de Aguas). 
De allí que consideramos que los mecanismos para reconocer características distintivas a las cooperativas que prestan servicios públicos, como así también promoverlas y fortalecerlas exige adecuar la regulación general de la actividad y los contratos de concesión y licencia a la realidad de las cooperativas de servicios públicos, y por ello consideramos adecuado sensibilizar en la necesidad de incorporar los puntos siguientes:

a) El uso del mecanismo de pass-through, es decir de traslación del incremento de costos a tarifa, sin necesidad de agotar la audiencia pública y la aprobación estatal o permitiendo que este último se realice con posterioridad. Los costos que debería permitirse trasladar directamente a tarifa al menos deberían ser el costo laboral y el aumento del insumo a distribuir ${ }^{36}$. Ello así porque son los dos principales componentes de la tarifa y de ese modo podríamos resguardar más eficazmente la ecuación económica financiera y, a su vez, evitaríamos la permanente injerencia del estado en la gestión de este tipo de entidades.

b) La posibilidad de que este tipo de prestadoras puedan ingresar en una facturación única junto al servicio que prestan, tanto el aporte de capitalización, como una alícuota sobre el total de la recaudación destinada a gastos institucionales. El aporte de capitalización permitirá mantener el capital adecuado y posibilitará hacer las inversiones que exige la ampliación y mantenimiento de las redes y el acceso irrestricto al servicio. Por su parte, los gastos administrativos ayudan al sostenimiento de la administración de estas entidades, de allí la importancia de permitir el ingreso de los mismos a una única factura. Además, si no se incorporaran dichos rubros a la factura del servicio, los mismos serían de difícil percepción y, además, las consecuencias de no hacer frente a ello, no permitiría que la cooperativa suspenda el servicio. No debemos olvidar que el interés de la cooperativa es compartido por los propios socios/usuarios, por lo que si se perjudica los intereses de la sociedad no se puede estar beneficiando los intereses del socio.

36 La firma del nuevo contrato de concesión del servicio de distribución eléctrica en la ciudad de Neuquén aprobado por Ordenanza n. 14178 da cuenta de que el Poder concedente ha incorporado la posibilidad de trasladar directamente sin autorización previa el aumento del costo de la energía y de los salarios. La inflación reinante en Argentina desde hace varios años exige este tipo de medida para resguardo de estas organizaciones y también en respeto de su propia identidad ya que son los mismos usuarios quienes la conforman y gestionan. 
La misma solución debe propiciarse para cuando la entidad presta varios servicios, en especial aquellos que tienen un importante contenido social, como sepelios, enfermería, entre otros, que si no se encuentran unidos al cobro del servicio público de principal distribución sería de muy difícil recaudación. Es justo que cuando una empresa de capital se encuentre prestando un servicio público, no se permita ingresar otros servicios a la facturación porque se restringe al consumidor la posibilidad de reclamar por la disconformidad de uno de los servicios sin poner en riesgo el normal funcionamiento del otro. Sin embargo, cuando son los propios usuarios los que decidieron que era importante para los socios y el conjunto de la comunidad la prestación de un servicio social especifico y, además, decidieron que el mismo sea incorporado a la factura del servicio principal porque de otro modo sería de difícil recaudación, tal principio general debería ceder, teniendo en cuenta la entidad de la cooperativa como instrumento a través del cual los asociados se autogestionan.

Por su parte, consideramos que se debe permitir el cobro con facturación única de otros servicios que prestan estas entidades, pero con la posibilidad de realizar pagos fraccionados, para evitar un mayor costo de administración.

c) Un régimen sancionatorio acorde con la condición de la cooperativa conformada por los propios usuarios del servicio público, donde se tenga en cuenta que quienes deben afrontar las sanciones son los propios asociados/usuarios. Postulamos que, en el caso de las normas regulatorias de la actividad, se permita moderar las sanciones, hacer quitas o implementar esperas, como mecanismos para armonizar dichas normas, con la doble condición de asociado y usuario.

d) Implementar audiencias públicas prácticas, sencillas y simplificadas para el supuesto de que la entidad superara los 5.000 asociados y su órgano de gobierno se encontrara conformado por delegados, mientras que para las cooperativas que no superaran dicho número debería obviarse dicho procedimiento frente a la semejanza de la audiencia con la reunión de los asociados en las asambleas.

\section{Adaptarse y adelantarse a los cambios tecnológicos}

La sobrevivencia de estas organizaciones dependerá de la habilidad de quienes lideran y gestiones el movimiento cooperativo para adap- 
tarse y adelantarse a los nuevos paradigmas que la sociedad posmoderna nos impone, entre ellos el cambio tecnológico.

Veamos entonces especialmente la situación de algunos servicios:

\section{a) LA TELEFONÍA FIJA}

La necesidad de adaptación de las cooperativas prestadoras de servicios públicos a las nuevas tecnologías es un hecho ineludible para garantizar la subsistencia de estas. Quizás, el mayor exponente de esta problemática y quien refleja la imperiosa necesidad de aggiornarse al mundo actual son las cooperativas prestadoras del servicio de telefonía fija.

Si bien es cierto que en aquellas ciudades argentinas con mayor cantidad de habitantes la telefonía fija se encuentra en manos de empresas privadas de capital, numerosas son las localidades que, aun hoy en día, suministran este tipo de servicios a sus usuarios a través del sistema cooperativo.

Ahora bien, las grandes empresas prestadoras del servicio, con una lógica mayor capacidad de inversión, han sabido reinventarse y extender su servicio hacia otras necesidades propias de los tiempos que corren como son el servicio de internet y de telefonía móvil.

Esta reinvención, en su gran mayoría, no se ha visto reflejada en las Cooperativas de Telefonía fija. No obstante, existen algunos supuestos que llevan una luz esperanzadora para la supervivencia de estas sociedades de cara al futuro.

Ejemplo de ello es la iniciativa presentada por la Cámara de Cooperativas de Telecomunicaciones (CATEL), quien presentó la marca Imowi, con la que brindará servicio de telefonía móvil a los socios integrantes de las cooperativas que nuclean este organismo que, en su totalidad, pertenecen a medianas y pequeñas localidades donde solo se brindaba el servicio de telefonía fija o, en algunos casos sumado internet y tv por cable ${ }^{37}$.

Para materializar esta adaptación a las nuevas tecnologías, es necesario generar grandes inversiones y en muchos casos desarrollar acuerdos con las empresas privadas de telecomunicaciones quienes son mayormente las que poseen la infraestructura tecnológica y las redes para que las cooperativas puedan brindar nuevos servicios.

37 https://catel.org.ar/imowi-sera-la-marca-del-cuarto-operador-de-telefonia-movilen-el-pais/ 


\section{b) LA ENERGía Y LA NECESIDAD DE GENERAR NUEVAS FUENTES SUSTENTABLES}

La necesidad de generar fuentes de energía sustentables que produzcan el menor impacto posible al medio ambiente ante el agotamiento de otras fuentes es un desafío para las cooperativas prestadoras de servicios de energía que han tenido y tienen que adaptarse a nuevas tecnologías para brindar de manera eficiente el suministro de energía y, a su vez, poder solventar los gastos que conlleva adquirir energía proveniente de este tipo de fuentes para poder distribuirla entre sus asociados sin generar un impacto considerable en las tarifas.

Con el objetivo marcado, haciendo eco de los valores cooperativos de responsabilidad social y el principio de compromiso con la comunidad para el cuidado del medio ambiente, es necesario que se promuevan, por ejemplo, redes inteligentes que permitan que los consumidores generen parte de su propia energía (por ejemplo, a través de paneles solares) y, así, enviar cualquier excedente de vuelta al sistema para que otros la usen. Este circuito no solo permitiría que la distribución se haga de manera más eficiente al no derramar energía eléctrica, sino también reduciría las tarifas a los usuarios domiciliarios, concentrando la energía para destinarla a la producción.

La Federación Argentina de Cooperativas Eléctricas (FACE) ha tomado cartas en el asunto entendiendo la problemática a la que se enfrentan hoy en día y ha impulsado el programa GECI (Generación Eléctrica de Cooperativas Integradas) que busca desarrollar centrales de generación de energía eléctrica que posibiliten el abastecimiento de los importantes incrementos de demanda que experimentan las cooperativas, con la utilización preferencial de recursos energéticos regionales, renovables y no contaminantes ${ }^{38}$.

En síntesis, iniciativas como la mencionada en el párrafo anterior, son sin dudas el camino a seguir para contrarrestar los efectos de los conflictos que enfrentan las cooperativas de servicios eléctricos como el agotamiento de los recursos energéticos no renovables, la baja eficiencia en las modalidades de consumo, los altos niveles de contaminación que contribuyen al calentamiento global, el impacto económico en las tarifas a los socios/usuarios y, consecuentemente, hacer frente a los costos de distribución de la manera más eficiente posible.

38 Gallo: «Cooperativas Eléctricas en Argentina. Perspectivas», https://www.aciamericas.coop/IMG/pdf/mgallo-2.pdf 


\section{c) El SERVICIO DE AGUA POTABLE Y CLOACAS}

El agua es un servicio público domiciliario básico y esencial para la vida de las personas y, por lo tanto, su suministro no puede ser interrumpido aun cuando exista falta de pago por parte de los usuarios, lo cierto es que esta última situación genera un grave problema para la subsistencia de las cooperativas prestadoras del servicio de agua.

Sabido es que, para la supervivencia de este tipo de organizaciones sociales, resulta fundamental el aporte que los socios puedan realizar en carácter de usuarios. De ello depende no solo la continuación de la cooperativa, sino también la capacidad de invertir para brindar un mejor y más eficiente servicio sin vulnerar los derechos de los usuarios/asociados.

Otro problema que las cooperativas prestadoras del servicio de agua identifican es la falta de actualización de las tarifas por parte de las autoridades provinciales, lo que repercute en una merma en la recaudación que luego se ve reflejada en las economías cooperativas. Huelga decir que este déficit, en la mayoría de los casos, debe ser soportado por las propias cooperativas al no recibir ningún tipo de ayuda o subsidio por parte del Estado 39 .

Así pues, de un lado encontramos la obligación inalterable de las cooperativas de no suspender el suministro de agua ${ }^{40}$, y del otro, la situación de falta de pago de los socios/usuarios que se suscita en numerosos casos; ya ello se le suma también que muchos gobiernos locales son los encargados de regular las tarifas que en muchas oportunidades resulta insuficiente para solventar los gastos por no mantenerse adecuadamente actualizadas. Esta combinación es hoy el mayor escollo que enfrentan este tipo de cooperativas y que ponen en peligro su subsistencia.

Sin embargo, el mayor desafío se concentra en encontrar y diseñar métodos más eficientes y menos costos de generación y distribución del agua potable, mantenimiento de redes y tratamiento de efluentes.

39 https://www.gestarcoop.com/novedades/noticias/34-mundo-cooperativo/609cooperativas-de-agua-y-saneamiento-de-la-provincia-analizaron-su-situacion.html https://www.elmiercolesdigital.com.ar/las-cooperativas-de-agua-tienen-complicacionespor-la-falta-de-actualizacion-tarifaria/

40 DNU del Poder Ejecutivo Nacional 311/20: Abstención de corte de Servicios en caso de mora o falta de pago. 
3. Generar políticas de integración asociativa y ampliar los horizontes de participación de los asociados

El modelo de gobierno democrático asegura que los intereses de sus socios impriman el funcionamiento y la trayectoria de las entidades, de modo que la composición y regulación de los órganos de gobierno y administración constituyen, en sí mismos, elementos fundamentales.

De allí que las importantes deficiencias en materia de gestión democrática, que fueron advertidas en el apartado 2.c), buscan poner en alerta de las tensiones que existen y procuran encontrar mecanismos que permitan fortalecer el sistema democrático de gobierno que es pilar en este tipo de entidades.

Recordemos que la participación democrática aparece como el logro de la integración asociativa, compuesta por la adhesión a las normas y valores de la comunidad constituida, mientras la debilidad democrática afecta directamente la integración misma de esta comunidad.

La baja participación de los asociados mediante el ejercicio de los derechos políticos y la aún más baja participación en la gestión genera un vacío de legitimidad. Sumado a ello, la participación de las mujeres es muy reducida en los órganos de administración de estas organizaciones. Así, para los nuevos liderazgos es un reto ampliar los horizontes e incorporar la participación de los asociados y extender los desafíos de la democracia paritaria a los órganos de administración de las cooperativas bajo estudio.

Ello se lograría con dirigentes formados en las bondades de la economía solidaria y con normas que promuevan mayor participación, en especial con normas positivas imperativas que obliguen a integrar la administración de las sociedades en paridad.

Por ello, consideramos que hay que poner foco en la problemática del gobierno corporativo. Las empresas sociales prestadoras de servicios públicos deben responder a un nuevo entorno económico, desarrollando innovaciones institucionales más adecuadas al momento que se vive y profundizando el modelo democrático.

En nuestra opinión la incorporación del buen gobierno corporativo vía legislativa o autorregulación debe incorporar al menos los tópicos que se indican seguidamente:

- Los mandatos de los administradores, síndicos y delegados deberían tener un límite de reelegilibilidad de dos períodos consecutivos, de tal manera que permita una mayor renovación de los 
cargos y, con ello, una mayor participación de la base asociativa en la dirección de estas entidades ${ }^{41}$.

- Tanto la normativa cooperativa, como los estatutos sociales deben incorporar la obligación de integrar el órgano de administración, de gobierno y de fiscalización paritariamente de conformidad, como lo ha regulado la Inspección General de Justicia de la Nación para ciertas sociedades y personas jurídicas a través de la Res. 34/202042.

- Como forma de promover los procesos de control se podrían implementar auditorías sociales y foros (aunque sea virtuales) que unan a los gerentes con los asociados y delegados ${ }^{43}$.

- La obligación de incorporar de las minorías debe ser la regla en el caso de las cooperativas bajo análisis.

- Los socios que pretendan postularse como candidatos a cubrir cargos en los órganos sociales de una cooperativa prestadora de servicios públicos no deberían formar parte de organismos estatales que tuvieran a su cargo la regulación y/o el poder de policía sobre la actividad que desarrolla la propia entidad.

\section{Sensibilizar sobre la necesidad de contar con nuevas herramientas para el financiamiento y la capitalización de estas entidades}

La actividad de las cooperativas prestadoras de servicios públicos exige continua inversión. Las cooperativas bajo la normativa reinante cuentan con muy pocos mecanismos para hacer frente a la necesidad de capital y financiamiento.

Además, en la medida que los marcos regulatorios y las leyes protectoras de los consumidores no permiten reflejar en las facturas del servicio, ítems ajenos a la prestación, hasta el aporte de capitalización se torna de difícil implementación.

41 El anteproyecto de Ley Federal de la Economía Solidaria significa un adelanto sobre el régimen vigente al señalar en el art. 67 que «los consejeros son reelegibles por tres períodos consecutivos o cinco alternados».

42 La mencionada resolución tiene alcance para las sociedades del Estado, sociedades de participación estatal mayoritaria, de economía mixta, sociedades que recurren al ahorro público, sociedades que son concesionarias del Estado y sus controlantes y controladas, y las Asociaciones Civiles, Simples Asociaciones y Fundaciones con excepciones.

43 Este mecanismo fue sugerido al abordar las medidas compensatorias sobre el poder de los cuadros directivos por Spear: «El gobierno democrático en las organizaciones cooperativas», CIRIEC-España, n. ${ }^{\circ} 48$, abril de 2004, p. 28. 
El movimiento cooperativo de servicios públicos debe sensibilizar sobre la necesidad de modificar la Ley de Cooperativas para permitir incluir en el texto nuevas formas de financiamiento y capitalización. A esos efectos se debe trabajar en pos de incorporar: a) El aporte voluntario independiente del uso de los servicios y que tengan el carácter de permanencia en el capital; b) La incorporación de socios que no participen de la actividad cooperativizada pero que colaboren con la consecución del objeto, a través del aporte de capital. Esta categoría de socio no se encuentra prevista en la legislación de cooperativas actual, aunque creemos que es un instrumento interesante para capitalizar y financiar a las cooperativas. El legislador debería incorporar en esta categoría a toda persona física o jurídica que tenga interés en participar y recibir a cambio una remuneración por el aporte voluntario al capital; c) Que el interés que se le reconozca tanto a socios plenos, como a aquellos no reúnen tal condición (llámese socios de apoyo o socios colaboradores), como contraprestación por el capital voluntario aportado sea acorde con el interés que pagan los bancos en el mercado. A nuestro modo de ver, la remuneración de los aportes voluntarios debe ser mixta, es decir compuesta por un interés que no debería ser inferior al que pagan los bancos por depósitos a plazo, como así también una participación en los resultados económicos de la actividad. Así, se obtendría una retribución por interés fijo y otra sujeta al desarrollo de la actividad, debiéndose imponer como límite una retribución del doble de la tasa de interés indicado como mínimo ${ }^{44}$. Creemos que ello respeta el principio cooperativo del interés limitado y convierte a estas aportaciones en instrumentos atractivos para los socios plenos, como para los socios que no reúnen tal calidad pero que colaboran con el aporte de capital; d) Incorporar como otro mecanismo de financiamiento las llamadas cuotas periódicas, que no son capital y que no son reintegrables. Éstas tienen en miras atender los gastos sociales o soportar inversiones que exige la entidad, que pueden ser de lo más variados. Aun cuando se puedan implementar sin necesidad de que la ley lo regule sería conveniente que así sea; e) Extender el financiamiento a través de obligaciones negociables a las cooperativas de consumo, en sintonía con lo que viene desarrollando la Comisión Nacional de Valores a través de la Resolución General 870/2020 de fecha 19 de noviembre de 2020 que resuelve incorporar como Sección X del Capítulo V del Título II de las NORMAS (N.T. 2013 y mod.), la posibilidad de que las

44 En similar sentido Fajardo García: «Las aportaciones voluntarias a capital social ante la reforma de la legislación cooperativa», CIRIEC-España, Revista de Economía Pública, Social y Cooperativa, n. ${ }^{\circ} 13,1993$. 
cooperativas de producción puedan solicitar a la Comisión autorización para la emisión de obligaciones negociables en forma individual o bajo la forma de programas globales. Esta es una gran herramienta para el desarrollo cooperativo y para promover un mercado de capitales federal, inclusivo, que permita canalizar el ahorro local hacia proyectos e inversiones con alto impacto en la economía real.

\section{Conclusiones}

Las cooperativas prestadoras de servicios públicos han marcado la historia de los pueblos y ciudades del interior de la República Argentina en el último siglo, su condición de pilar del desarrollo del interior de la argentina en la posmodernidad dependerá de cómo enfrentan los desafíos que se les presentan. La innovación tecnológica, los cambios de servicios, las nuevas demandas sociales, la falta de financiamiento y de capital, el desinterés del Estado en fortalecer este modelo y en comprender la naturaleza diferenciada a la hora de regular y diseñar contratos de concesión, la indiferencia de los vecinos en la gestión y la falta de integración asociativa son temas centrales que exigen de sus líderes mayor formación, creatividad y disposición emprendedora.

Las cooperativas prestadoras de servicios públicos son empresas, pertenecientes a la economía social, pero empresas al fin. Su sustentabilidad depende de que puedan producir bienes y servicios a un precio justo para satisfacer las necesidades dinámicas de sus asociados. Dependerá de que puedan lograr ese objeto-fin, que también puedan llegar a satisfacer el interés general, y ello exige adecuarse a los nuevos tiempos que la posmodernidad impone. Un gran desafío que apostamos a que puedan lograr.

\section{Bibliografía}

AmAR, Jacobo: Política y cooperativas, Ed. Instituto, Rosario, 1965.

Callejo, Alfredo V.: Los principios cooperativos y las cooperativas de servicios públicos, Ed. Intercoop, Buenos Aires, 1998.

COMADIRA, Julio R.: «El derecho administrativo como régimen exorbitante en el servicio público», en Servicio Público, Policía y Fomento, Ediciones RAP, Buenos Aires, 2003.

Cracogna, Dante: Problemas Actuales del Derecho Cooperativo, Ed. Intercoop,

Buenos Aires, 1992. 
FAJARDO GARCía, Isabel G.: «Las aportaciones voluntarias a capital social ante la reforma de la legislación cooperativa», CIRIEC-España, Revista de Economía Pública, Social y Cooperativa n. 13, 1993.

FredianI, Ramón; BRANDA, Luis; Sesin, Domingo; Ingaramo, Eduardo: Transferencia de Servicios Públicos a Empresas Cooperativas, Ed. Intercoop, Buenos Aires, 1986.

Galto, Marcelo: "Cooperativas Eléctricas en Argentina. Perspectivas», https:// www.aciamericas.coop/IMG/pdf/mgallo-2.pdf

GUARCO, Ariel: El cooperativismo argentino, Ed. Intercoop, Buenos Aires, 2014.

Pérez Hualde, Alejandro: «Servicios Públicos, Régimen, Regulación y Organismos de Control», en Pérez Hualde, Alejandro (dir.): Servicios Públicos y Organismos de Control, Ed. Lexis Nexis, Buenos Aires, 2005.

SPEAR, Roger: «El gobierno democrático en las organizaciones cooperativas», CIRIEC-España, n. ${ }^{\circ}$ 48, abril de 2004, p. 28. 


\section{Derechos de autor}

La revista Deusto Estudios Cooperativos es una revista de acceso abierto lo que significa que es de libre acceso en su integridad inmediatamente después de la publicación de cada número. Se permite su lectura, la búsqueda, descarga, distribución y reutilización legal en cualquier tipo de soporte sólo para fines no comerciales y según lo previsto por la ley; sin la previa autorización de la Editorial (Universidad de Deusto) o el autor, siempre que la obra original sea debidamente citada (número, año, páginas y DOI si procede) y cualquier cambio en el original esté claramente indicado.

\section{Copyright}

The Deusto Journal of Cooperative Studies is an Open Access journal which means that it is free for full and immediate access, reading, search, download, distribution, and lawful reuse in any medium only for non-commercial purposes, without prior permission from the Publisher or the author; provided the original work is properly cited and any changes to the original are clearly indicated. 